\title{
Selective conversion of glycerol into propylene: Single-step vs. tandem process
}

Zhijie $\mathrm{Wu}^{*}{ }^{\dagger}, \star$, Kaiqiang Zhao ${ }^{\dagger}$, Shaohui Ge ${ }^{\S}$, Zhi Qiao ${ }^{\dagger}$, Jinsen $\mathrm{Gao}^{\dagger}$, Tao Dou ${ }^{\dagger}$, Alex C.K. Yip*,\|, Minghui Zhang*,

${ }^{\dagger}$ State Key Laboratory of Heavy Oil Processing and Key Laboratory of Catalysis of CNPC, China University of Petroleum, 18 Fuxue Road, Changping, Beijing 102249, China

$\$$ Key Laboratory of Advanced Energy Materials Chemistry (Ministry of Education), Nankai University, 94 Weijin Road, Tianjin 300071, China

§Petrochemical Research Institute, PetroChina Company Limited, E318, A42 Block, China Petroleum innovation base, Changping, Beijing 100195, China

" Department of Chemical and Process Engineering, University of Canterbury, Christchurch 8140, New Zealand

E-mail: zhijiewu@cup.edu.cn; alex.yip@canterbury.ac.nz; zhangmh@nankai.edu.cn

The supporting information consists of 6 pages, 4 figures. 


\section{Description of the characterization methods.}

Powder X-ray diffraction (XRD) patterns of the obtained samples were collected on a Bruker AXS D8 ADVANCE X-ray diffractometer with $\mathrm{Cu} \mathrm{K} \alpha$ radiation $(\lambda=1.5406$ $\AA, 40 \mathrm{kV}, 40 \mathrm{~mA}$ ) at a scanning rate of $5 \%$ min in the range of $5-35^{\circ}(2 \theta)$. The size and morphology of as-synthesized samples were observed on a Hitachi S-4800 field-emission scanning electron microscope (SEM).

The coke content of the spent catalyst was evaluated by thermogravimetric analysis (TGA) on a Netzsch STA 409 PC analyzer. TG analysis was performed in nitrogen flow at a heating rate of $10 \mathrm{~K} \mathrm{~min}^{-1}$ from room temperature to $1,073 \mathrm{~K}$. The weight loss in the temperature region from $323-473 \mathrm{~K}$ is ascribed to the release of adsorbed water and some volatile organic compounds, whereas the weight loss occurring from 573-973 $\mathrm{K}$ is ascribed to the combustion of coke deposition and may be considered the total coke content of the sample.

The chemical composition of the coke compositions was measured by the method developed by Guisnet and co-workers. ${ }^{[1]}$ First, the coked zeolite sample was treated by dichloromethane $\left(\mathrm{CH}_{2} \mathrm{Cl}_{2}\right)$ under reflux for $12 \mathrm{~h}$. Then, the carbonaceous compounds were liberated from the zeolite by dissolution of the aluminosilicate matrix in a HF solution (20\%) at room temperature. Subsequently, the soluble components were extracted with $\mathrm{CH}_{2} \mathrm{Cl}_{2}$. The resulting organic phases were analyzed by GC-MS on an Agilent 7890-5975C MSD. An Agilent HP-5 capillary column (60 m $\times 0.25 \mathrm{~mm}$ i.d. $\times 0.25 \mu \mathrm{m}$ film thickness) was used. An initial oven temperature of $323 \mathrm{~K}$ was maintained for $1 \mathrm{~min}$. Then, a ramping rate of $10 \mathrm{~K} \mathrm{~min}^{-1}$ was implemented to reach a final column temperature of $553 \mathrm{~K}$. This temperature was maintained for $10 \mathrm{~min}$.

\section{Reference}

[1] Guisnet, M.; Costa, L.; Ribeiro, F. R. Prevention of zeolite deactivation by coking. J. Mol. Catal. A, 2009, 305, 69-83. 


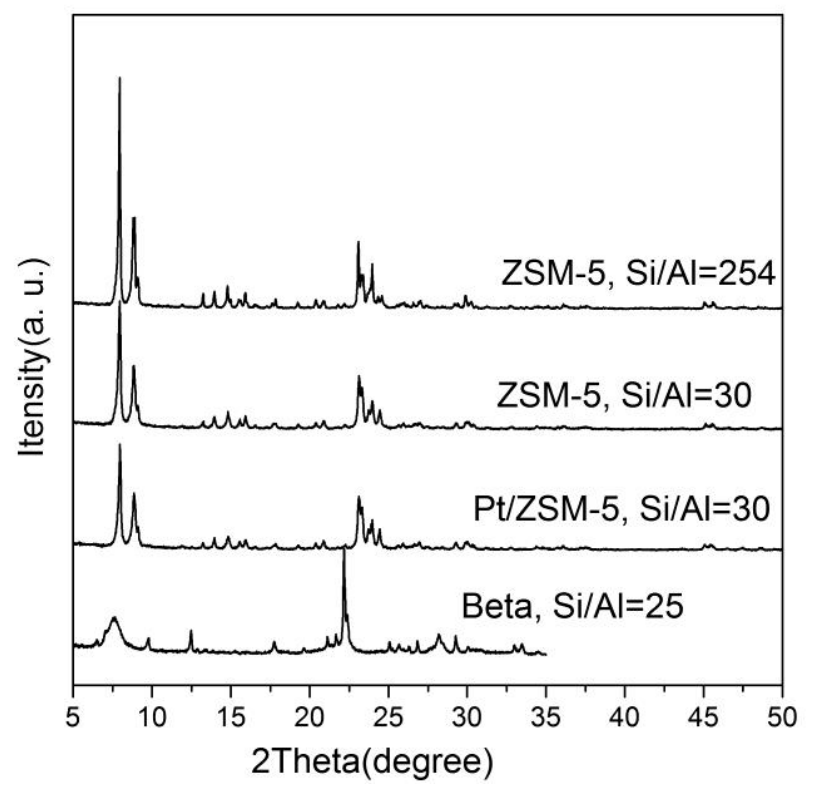

Figure S1. XRD patterns of zeolite samples and zeolite supported Pt catalysts. 


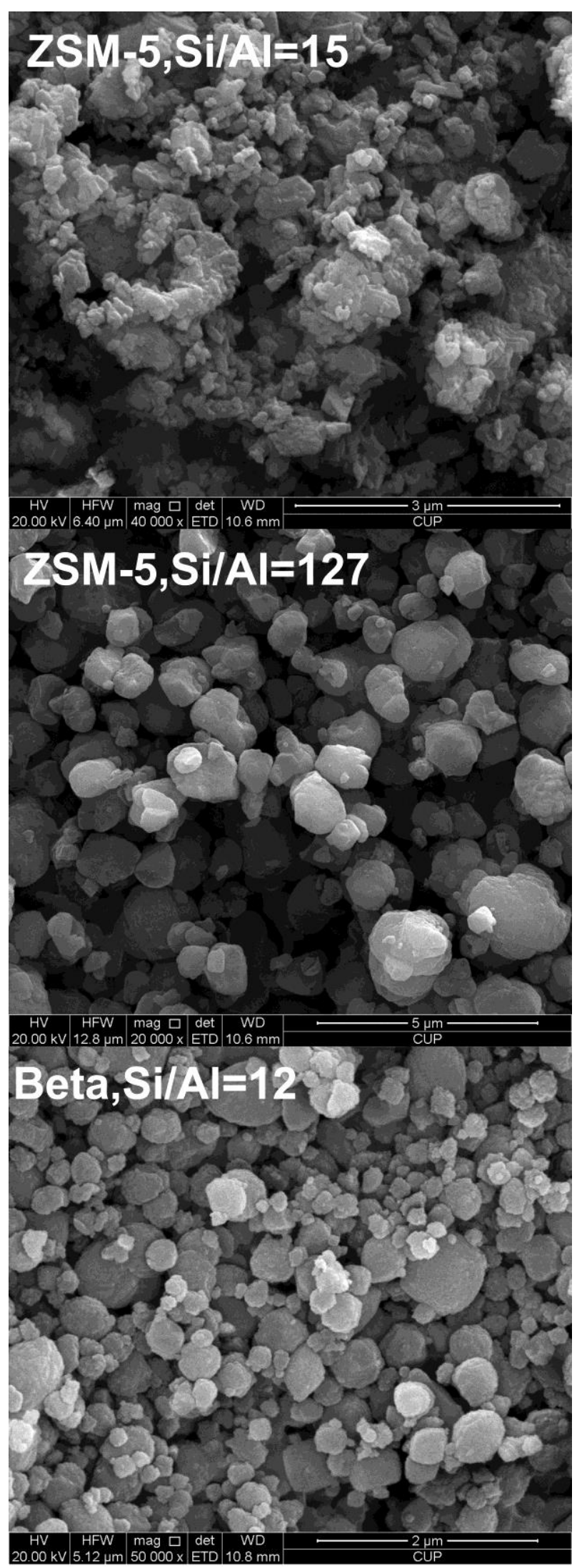

Figure S2. SEM images of zeolite samples. 


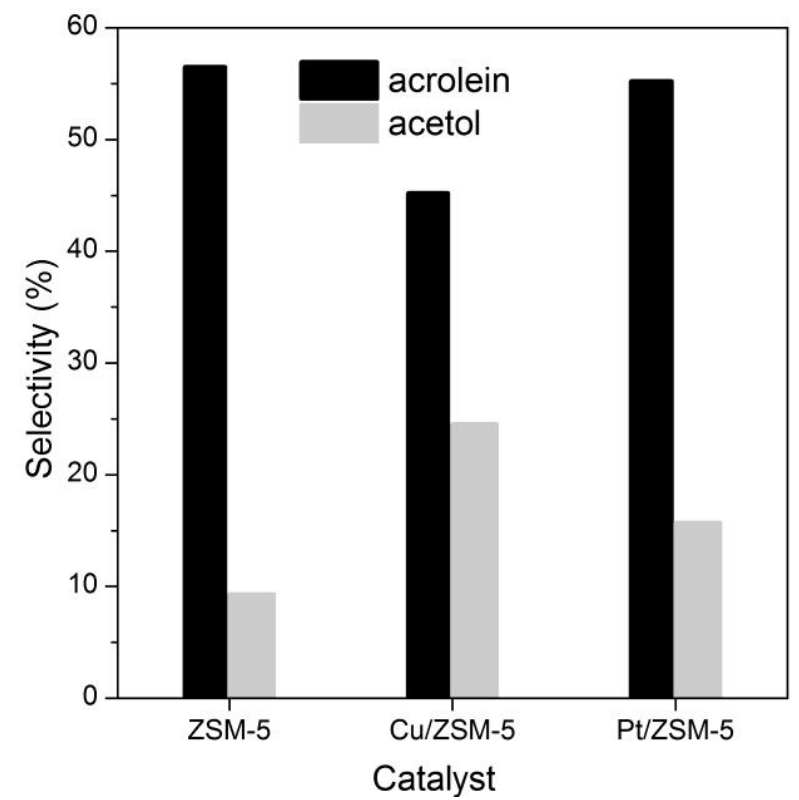

Figure S3. Selectivities for acrolein and acetol in the dehydration of glycerol with $\sim 80 \%$ conversion over ZSM-5 (Si/Al=15) based catalysts (21.9 kPa glycerol, $78.1 \mathrm{kPa}$ $\left.\mathrm{H}_{2} \mathrm{O}\right)$. 


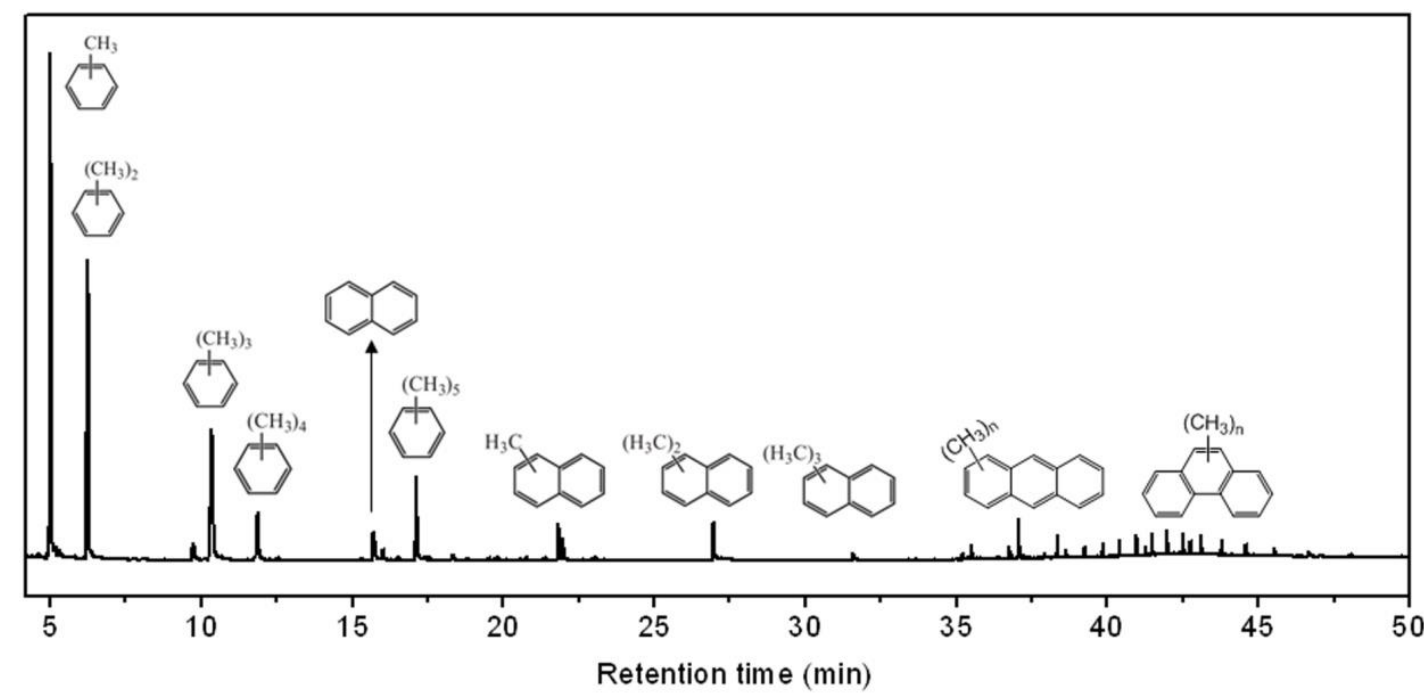

Figure S4. Gas chromatogram of the carbonaceous compounds formed in the deactivated MTP catalysts in Figure 11. 